\title{
Successful Treatment of a Dilated Circumflex Artery and Coronary Sinus Fistula
}

\author{
Alexander Martin Bernhardt ${ }^{1}$ Helmut Gulbins ${ }^{1}$ Hermann Reichenspurner ${ }^{1}$ \\ ${ }^{1}$ Department of Cardiovascular Surgery, University Heart Center \\ Hamburg, Hamburg, Germany \\ Thorac Cardiovasc Surg Rep 2013;2:2-5.

\begin{abstract}
Address for correspondence Alexander Martin Bernhardt, MD, Department of Cardiovascular Surgery, University Heart Center Hamburg, Martinistrasse 52, Hamburg 20246, Germany (e-mail: al.bernhardt@uke.de).
\end{abstract}
Abstract
Keywords
- fistula
- coronary sinus
- circumflex artery
- coronary artery aneurysm
- CABG

Coronary arteriovenous fistula is a rare entity and is mostly diagnosed and corrected in early childhood. We report the case of a 59-year-old female patient who was presented with chest pain during exertion for 3 months because of an aneurysmatic circumflex artery and coronary sinus fistula. We successfully ligated the circumflex artery close to the main stem and to the coronary sinus. The first marginal branch was revascularized by the left internal thoracic artery. The postoperative course was uneventful.

\section{Introduction}

Coronary arteriovenous fistulas (CAVFs) are rare. The frequency of CAVF among patients undergoing coronary angiography or coronary computed tomography is reported to be between 0.1 and $0.8 \%{ }^{1,2}$ About $55 \%$ of fistulas originate from the right coronary artery (RCA), $40 \%$ from the left main artery, and $5 \%$ from both. The most common draining sites are the pulmonary artery (12-80\%), right ventricle (7-40\%), coronary sinus ( $7 \%$ ), and left atrium (5\%), left ventricle (3\%), or superior vena cava (1\%). Fistulas from the circumflex artery draining to the coronary sinus are rare. ${ }^{1-4}$

\section{History}

A 59-year-old female patient complained of progredient chest pain, dyspnoea, and palpations on exertion for 3 months. She never had these symptoms before. Her medical history consisted of obesity, diabetes, and obstructive sleep apnoea. Her medication consisted of $\beta$-blockers, angiotensinconverting-enzyme inhibitor, and hydrochlorothiazide. She was a nonsmoker and consumed alcohol occasionally. She was a homemaker and lived with her husband and two children.

received

February 6, 2013

accepted after revision

May 7, 2013

published online

July 16, 2013 10.1055/s-0033-1348062. ISSN 2194-7635.

\section{Examination}

Examination revealed no abnormalities. Blood pressure was within the limits. In ECG examination she was in sinus rhythm, ST segments were not markedly changed. Cardiac enzymes were not elevated. Transthoracic echocardiography showed a good biventricular function without regional movement disturbances with competent valves and no dilated cardiac chambers. In the coronary angiography, the circumflex artery was dilated and presented with a fistula to the coronary sinus (-Figs. 1 and 2). A contrast enhanced CT scan confirmed the diagnosis of a coronary sinus fistula (-Figs. 3 and $\mathbf{4}$ ). We performed no additional diagnostics to evaluate ischemia in terms of stealing effects and ischemia.

\section{Operation}

After median sternotomy, the left internal thoracic artery was prepared in skeletonized technique. After cannulation of upper and lower vena cava and distal ascending aorta, extracorporeal circulation was started. We decided to perform the operation via median sternotomy and with bicaval cannulation to enable optimal visualization of the aneurysmatic fistula and, in case of preoperative

\footnotetext{
(c) 2013 Georg Thieme Verlag KG Stuttgart · New York
}

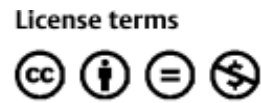




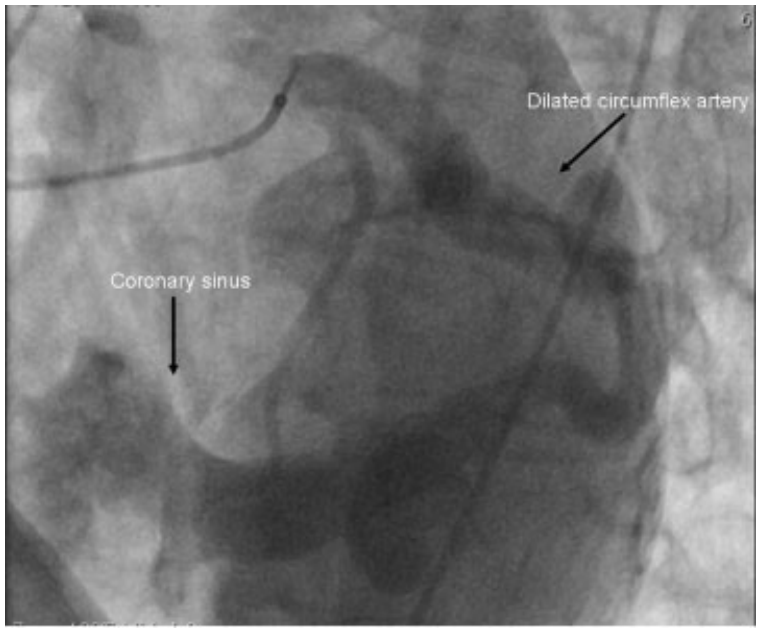

Fig. 1 Coronary sinus fistula seen in left heart catheterization.

undiagnosed distal coronary sinus entries, on the orifice of the coronary sinus after opening of the right atrium or the aneurysmatic coronary artery. Aorta was cross-clamped and the heart was arrested by antegrade cold blood-cardioplegia. The aneurysmatic circumflex artery was prepared and ligated below the main stem and the coronary sinus (-Figs. 5 and 6). The first marginal branch was revascularized by the left internal thoracic artery to supply blood to three smaller marginal branches. Intraoperative course was uneventful and transesoephageal echocardiography showed no changes to the preoperative status. The patient was transmitted to intensive care unit (ICU) without inotropic support in sinus rhythm.

\section{Postoperative Course}

The patient was extubated a few hours after admission to ICU. No bleeding or rhythm disturbances occurred. She was transferred to ward on postoperative day (POD) 1. Cardiac enzymes were not elevated in an unusual fashion. Renal function was

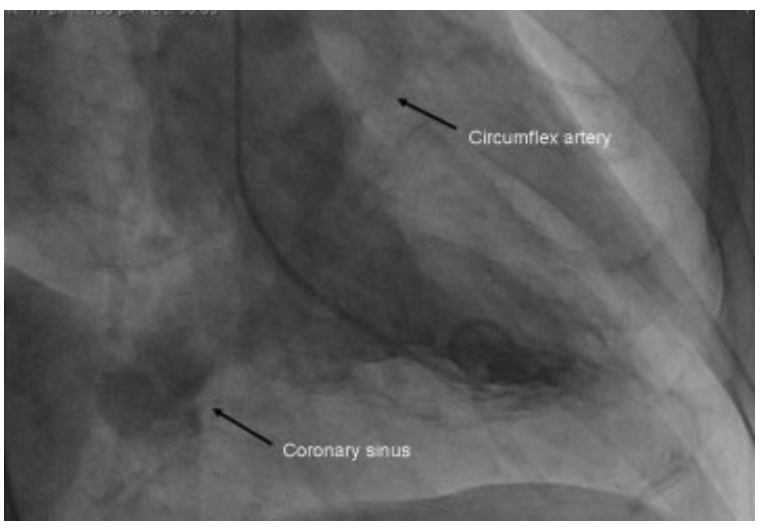

Fig. 2 Coronary sinus fistula seen in levocardiography.

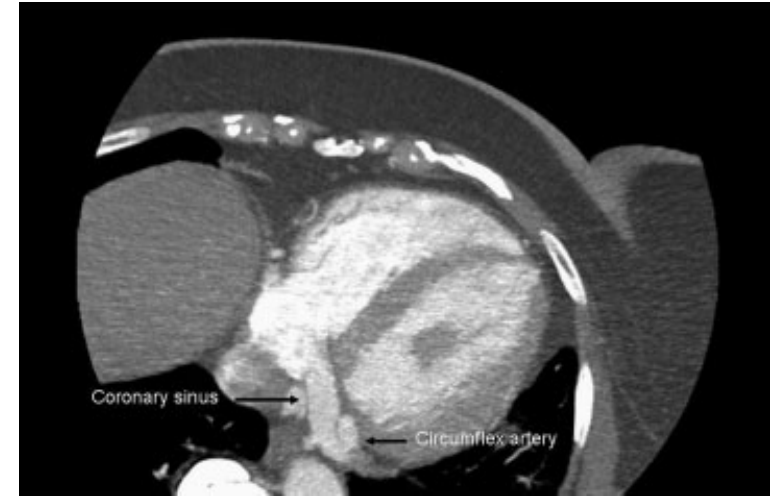

Fig. 3 Computed tomographic scan showing an aneurysmatic circumflex artery and coronary sinus fistula.

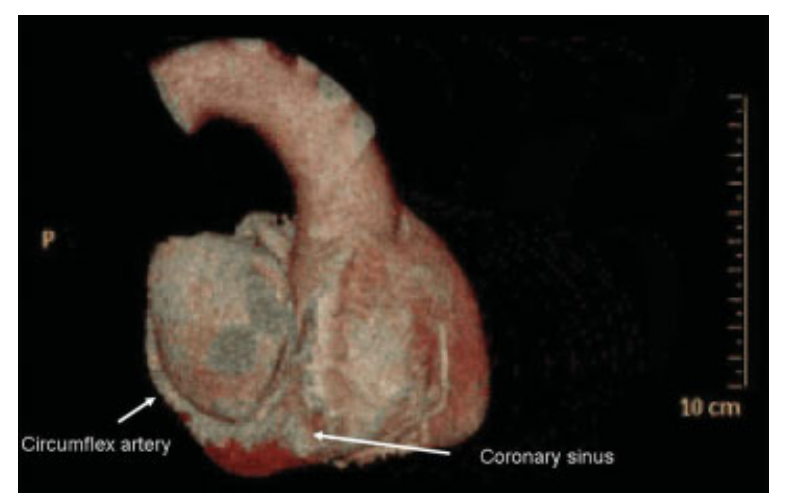

Fig. 4 Three-dimensional reconstructed computed tomographic scan showing a coronary sinus fistula.

not impaired during hospital stay. At discharge on POD 6 to a rehabilitation facility, the patient was in sinus rhythm with an unchanged good biventricular function. Anticoagulation regime consisted of a dual antiplatelet therapy with aspirin (ASA) $100 \mathrm{mg}$ once daily and clopidogrel $75 \mathrm{mg}$ once daily for

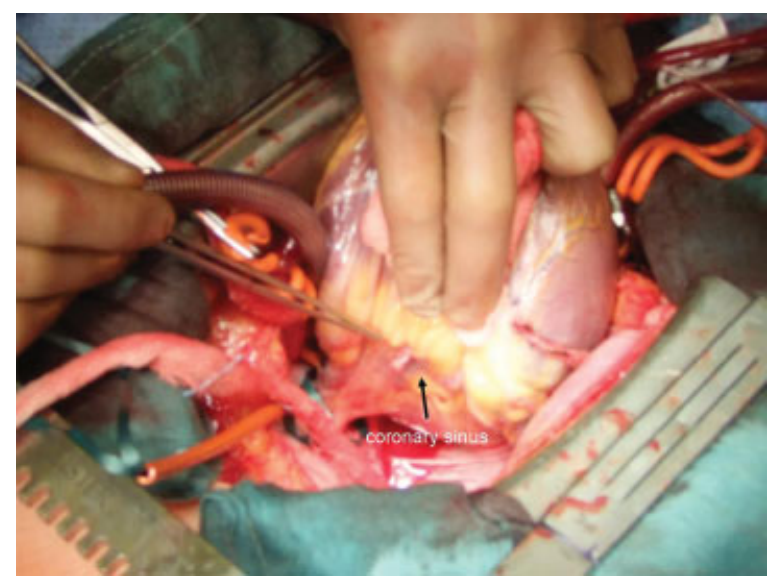

Fig. 5 Intraoperative view on an aneurysmatic circumflex artery and coronary sinus fistula. 
4 Treatment of Circumflex Artery and Coronary Sinus Fistula Bernhardt et al.

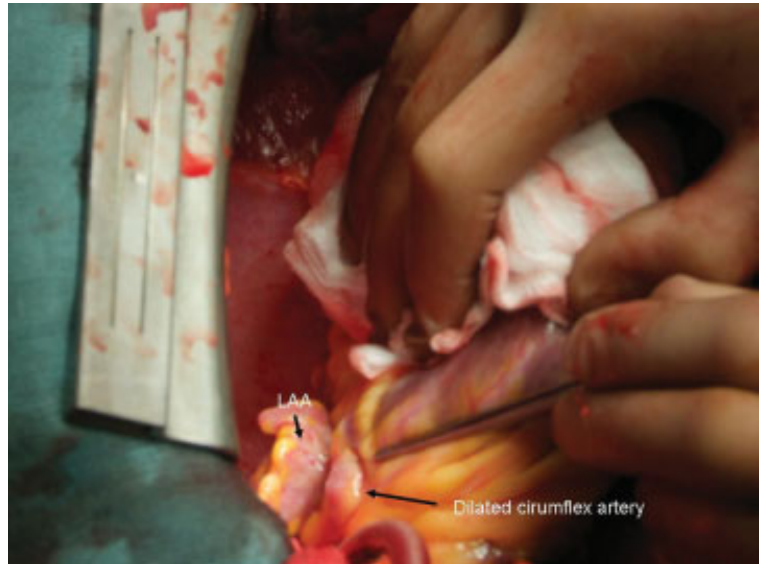

Fig. 6 Intraoperative view on an aneurysmatic circumflex artery and coronary sinus fistula. LAA, left atrial appendage.

4 weeks postoperatively followed by ASA $100 \mathrm{mg}$ once daily lifelong. After 8 weeks, her functional status was not impaired and she was relieved from chest pain.

\section{Discussion}

The presence of arteriovenous coronary artery fistula were first described by Krause in $1865 .{ }^{5}$ The first operation was done by Biörck and Crafoord. ${ }^{6}$ CAVF is a rare entity and is mostly diagnosed and corrected in early childhood. Most repairs of coronary AV fistulas in childhood are in conjunction with other congenital problems. Some are asymptomatic in childhood and become manifest in adults. Percutaneous closure of coronary fistulas has been reported, but these techniques do not eliminate the risk for rupture of the aneurysmal circumflex artery in this case. ${ }^{4}$ We discussed the patient within the interdisciplinary heart team as also proposed by recent guidelines for myocardial revascularization. In our case of a large and wide fistula with a high-flow shunt, we decided that an interventional or minimally invasive approach is not the optimal treating strategy in accordance with previous reports. ${ }^{7}$ The evidence on the natural course of coronary artery fistulas and coronary aneurysm is low. Most reports describe a low rate of complications and recommend conservative treatment. However, in cases of symptomatic patients and high-flow arteriovenous shunts closure is recommended to prevent complications such as rupture, heart failure, myoardial ischemia, and endocarditis. ${ }^{8,9}$ Coronary aneurysm is often associated with coronary artery stenosis and the natural course is controversial. One study showed that coronary aneurysm does not confer added risk in patients with coexisting obstructive coronary artery disease and those patients with pure ectasia have a good prognosis. ${ }^{10}$ Another study found aneurysms to be an independent predictor of mortality, with $71 \%$ of patients surviving after 5 years. ${ }^{11}$ We decided to ligate the aneurysm and shut it off from perfusion. We chose to revascularize a large marginal branch to provide blood to some smaller marginal branches. We used the left internal thoracic artery because of the best graft patency and a young patient with normal life expectancy. We did not resect the aneurysm although there have been successful surgical case reports in which the nonarteriosclerotic right coronary aneurysm draining to the right ventricle was resected under cardiopulmonary bypass, the arteriovenous fistula was ligated from inside the coronary aneurysm, and coronary artery bypass grafting was done in the normal portion of distal RCA using saphenous vein graft. ${ }^{12}$ We closed the fistula from the outside, although other report closure from inside the coronary sinus. $^{13}$

\section{Conclusion}

Arteriovenous coronary artery fistula of a dilated circumflex artery draining into the coronary sinus can be successfully treated by ligation of the circumflex artery and revascularisation of the first marginal branch.

\section{Disclosures}

There is no conflict of interest to be stated by any of the authors.

\section{References}

1 Cheung DL, Au WK, Cheung HH, Chiu CS, Lee WT. Coronary artery fistulas: long-term results of surgical correction. Ann Thorac Surg 2001;71(1):190-195

2 Gillebert C, Van Hoof R, Van de Werf F, Piessens J, De Geest H. Coronary artery fistulas in an adult population. Eur Heart J 1986;7 (5):437-443

3 Fernandes ED, Kadivar H, Hallman GL, Reul GJ, Ott DA, Cooley DA. Congenital malformations of the coronary arteries: the Texas Heart Institute experience. Ann Thorac Surg 1992; 54(4):732-740

4 Reidy JF, Anjos RT, Qureshi SA, Baker EJ, Tynan MJ. Transcatheter embolization in the treatment of coronary artery fistulas. J Am Coll Cardiol 1991;18(1):187-192

5 Krause W. Uber den Ursprung einer akzessorischen A. Coronaria aus A. Pulmonalis. Z Ratl Med 1865;24: 225-227

6 Biörck G, Crafoord C. Arteriovenous aneurysm in the pulmonary artery simulating patent ductus arteriosus botalli. Thorax 1947;2:65-90

7 Mangukia CV. Coronary artery fistula. Ann Thorac Surg 2012;93 (6):2084-2092

8 Sommer RJ, Hijazi ZM, Rhodes JF Jr. Pathophysiology of congenital heart disease in the adult: part I: Shunt lesions. Circulation 2008;117(8):1090-1099

9 Balanescu S, Sangiorgi G, Castelvecchio S, Medda M, Inglese L. Coronary artery fistulas: clinical consequences and methods of closure. A literature review. Ital Heart J 2001;2(9): 669-676

10 Demopoulos VP, Olympios CD, Fakiolas CN, et al. The natural history of aneurysmal coronary artery disease. Heart 1997;78 (2):136-141

11 Baman TS, Cole JH, Devireddy CM, Sperling LS. Risk factors and outcomes in patients with coronary artery aneurysms. Am J Cardiol 2004;93(12):1549-1551 
12 Saxena P, Konstantinov IE, Burstow D, Tam R. Surgical repair of a large coronary artery aneurysm with arteriovenous fistula. J Thorac Cardiovasc Surg 2006;131(5):11671168
13 Nakayama Y, Shikawa A, Ayusawa Y, et al. Surgical repair of complicated coronary arteriovenous fistula and coronary artery aneurysm in an elderly patient after 26 years of conservative therapy. Heart Vessels 2011;26(1):111-116 